\title{
"ESCOLHO ME VER AGORA": NOTAS SOBRE UMA EXPERIÊNCIA DE ESCRITA DE SI NA FORMAÇÃO DE PROFESSORES
}

\author{
Avelino Aldo de Lima Neto ${ }^{1}$ \\ Hugo Filgueiras de Araújo ${ }^{2}$ \\ Patrícia Carla de Macedo Chagas ${ }^{3}$
}

\begin{abstract}
Resumo:
O presente artigo objetiva, a partir de uma perspectiva fundamentada em estudos autobiográficos e narrativos, apresentar algumas notas sobre a escrita de si através de uma experiência pedagógica que articulou o cinema e o diário na formação de professores. Para tanto, inicialmente, são apontados alguns lugares do corpo e do discurso no contexto da cultura de si. Logo após, a experiência do olhar nessa mesma ambiência é desvelada. Num terceiro momento, a partir dos textos foucaultianos, é salientada a possibilidade de uma dimensão visual da escritura e a sua relação com a transformação operada nos sujeitos-corpos que, em nosso caso, são licenciandas. Por fim, são sublinhados alguns elementos oriundos dessa experiência, com vistas a pensar a possibilidade de outras ferramentas teórico-empíricas capazes de colaborar eficazmente no trajeto da formação docente. A associação entre o cinema e os diários mostrou-nos ser possível conectar a experiência vivida aos saberes acadêmicos na prática do cuidado e do narrar de si como experiências propositivas para o devir da profissão docente no processo de formação inicial.
\end{abstract}

Palavras-chave: Foucault; escrita; subjetivação; imagem; formação docente.

\section{«JE CHOISIS DE ME VOIR MAINTENANT»: NOTES SUR UNE EXPÉRIENCE D'ÉCRITURE DE SOI DANS LA FORMATION DE ENSEIGNANTS}

\section{Résumé:}

Cet article vise, dans une perspective basée sur des études autobiographiques et narratives, à présenter quelques notes sur l'écriture de soi à travers une expérience pédagogique qui a articulé le cinéma et le journal intime dans la formation des enseignants. A cette fin, dans un premier temps, certains lieux du corps et du discours sont mis en évidence dans le contexte de la culture de soi. Ensuite, l'expérience du regard dans ce même contexte est dévoilée. Dans un troisième moment, basé sur des textes foucaldiens, il est mise en évidence la possibilité d'une dimension visuelle de l'écriture et sa relation avec la transformation opérée dans les sujets-corps qui, dans notre cas, sont les étudiants en formation pour devenir enseignants. Enfin, certains éléments tirés de cette expérience sont présentés, en vue de réfléchir à la possibilité d'autres outils théoriques et empiriques capables de collaborer efficacement sur le chemin de la formation des enseignants. L'association entre le cinéma et les journaux intimes nous a montré qu'il est possible de relier l'expérience vécue aux connaissances académiques dans la pratique du souci et de la narration de soi en tant qu'expériences propositives pour le devenir même du métier d'enseignant dans le processus de formation initiale.

Mots-clés : Foucault; écriture; subjectivation; image; formation des enseignants.

1 Doutor em Educação pela Université Paul Valéry - Montpellier III e pela Universidade Federal do Rio Grande do Norte (UFRN). Professor de Filosofia do Instituto Federal de Educação, Ciência e Tecnologia do Rio Grande do Norte (IFRN) e dos Programas de Pós-Graduação em Educação Profissional (PPGEP/IFRN) e em Educação (PPGEd/UFRN). Email: ave.neto@ hotmail.com.

2 Pós-doutor pela National and Kaposdistrian University of Athens. Doutor em Filosofia pelo Programa Integrado UFPB-UFRN-UFPE. Professor do Curso de Filosofia e do Programa de Pós-Graduação em Filosofia (PPGFIL) da Universidade Federal do Ceará (UFC). Email: hugofilguaraujo@ hotmail.com

3 Doutora em Ciências da Educação pela Universidade do Minho. Professora de Didática do Instituto Federal de Educação, Ciência e Tecnologia do Rio Grande do Norte (IFRN). Email: patriciacfaria@gmail.com. 
Avelino Aldo de Lima Neto / Hugo Filgueiras de Araújo / Patrícia Carla de Macedo Chagas

\section{Introdução}

Constituir-se historicamente enquanto experiência, isto é, como algo que pode e deve ser pensado (FOUCAULT, 1984, p. 13), é tema investigado pelo renomado pensador francês, notadamente nos seus últimos cursos no Collège de France. Essa investigação inserese, sabemo-lo, no terceiro eixo de exploração de uma história crítica do pensamento, tendo como foco a fabricação ética do sujeito. Trata-se de uma história compreendida como emergência dos jogos de verdade na qual o próprio sujeito é posto como objeto de saber possível (FOUCAULT, 2001c, p. 1450-1452). Tal experiência, que na Antiguidade Greco-Romana era de natureza ética e estética ${ }^{4}$, tomou como superfície de refração o uso dos prazeres do VI século a.C. ao II século d.C, período do nascimento e desenvolvimento da cultura de si. Nesse ínterim, Foucault explorou diversas artes da existência que compunham o amplo quadro do cuidado de $s i$, dentre as quais situou-se a prática da escritura de si, da qual o nosso diário se aproximou enquanto ferramenta pedagógica, conforme explicaremos posteriormente.

Por outro lado, desde os anos cinquenta, o tema da imagem atravessa obliquamente a obra foucaultiana. Da nau de Bosch na História da Loucura até as entrevistas nos Cahiers du Cinéma, o que está em questão é a instalação de uma nova inteligência, que transforma o arquivo em cenário ao fazer nascer dos suportes do visível uma outra inteligibilidade (IMBERT, 2004; LIMA NETO, 2018). Para além do olhar panóptico, é um olhar transóptico que se inaugura, desvelando modos outros de ver (TEIXEIRA; CAMINHA; LIMA NETO, 2017). Seja na escrita de si, seja na imagem, surge uma outra relação com a verdade, perturbando o sujeito e exigindo-lhe uma transformação que passa, inevitavelmente, pelo corpo enquanto "superfície de inscrição dos acontecimentos" e de "dissociação do Eu", ponto de encontro entre a história e os processos de subjetivação (FOUCAULT, 1979, p. 22).

4 O princípio da reflexão sobre um pensamento subjetivo, um olhar sobre si mesmo, dentro da cultura clássica é a máxima délfica "Conhece-te a ti mesmo!". Essa reflexão compreendia uma possibilidade de uma integração entre as instâncias constitutivas do ser humano - a alma e o corpo - através de um processo de conhecimento de si, a fim de facilitar a vida política. A partir da filosofia socrático-platônica, a concepção de "eu", que anteriormente, no pensamento homérico (ROBINSON, 2010, p. 58), era centrada numa visão do corpo (sôma) como identidade própria do ser humano, deu lugar à noção de alma ( $p s y k h e ́)$, que passou, na sua interlocução dialética e relacional com o corpo, a ser entendida como aquilo que, futuramente, pode ser chamado de sujeito. Essa nova compreensão redimensiona os aspectos da educação grega (paidéia), que a partir de então passou a entender a música e a filosofia como componentes da educação da alma e a ginástica para a educação do corpo. (Ver República 376ss; Timeu 87-88).

\begin{tabular}{|l|l|l|l|l|}
\hline Qevista Dialectus & Ano 9 & n. 16 & Janeiro-Abril 2020 & p. $65-81$ \\
\hline
\end{tabular}


Partindo dessa articulação teórica entre o olhar, a subjetivação e a escrita, foi desenvolvida uma experiência pedagógica através das disciplinas de Língua Portuguesa ${ }^{5}$ e Ética numa turma de Licenciatura em Educação do Campo (LEDOC). No início do ano acadêmico, exibiu-se o filme Escritores da Liberdade (2007). O conhecido longa é baseado nos diários escritos pelos alunos da sala 203 da Woodrow Wilson H. S, escola da periferia de Los Angeles. A instituição localizava-se numa área de tensão entre gangues. Os alunos, que à época tinham entre 14 e 15 anos, recebem uma nova professora de Língua Inglesa, chamada Erin Gruwell. A partir da Literatura, a turma começa a vislumbrar outra vida a partir da produção de um diário.

$\mathrm{Na}$ aula que se seguiu à exibição do filme, houve a partilha de impressões, discutindo-se, entre outros aspectos, sobre a escrita como prática social, bem como sobre o papel por ela desempenhado enquanto técnica fundadora de um ethos.

A partir de então, solicitou-se dos estudantes a escrita de um diário ao longo do semestre. Nele deveriam ser enfocados dois aspectos: de um lado, o conjunto de experiências que iriam marcar aquele início de itinerário na formação docente; de outro, a realidade das comunidades nas quais eles desenvolviam suas atividades.

Fizemo-lo com o objetivo de, ao promover uma experiência na qual os sujeitos se tomam eles mesmos por objetos do conhecimento, diagnosticar os modos através dos quais agem sobre si face aos desafios da formação inicial de professores. A partir desse escopo, escolhemos dois diários para melhor apreciarmos essa relação. O critério para essa seleção foi a maior fidelidade possível àquilo que se demandou em relação à escrita do diário.

No que concerne às técnicas para coleta de dados, enfatizamos que a estratégia dos diários solicitados traz "ideias sobre os sentimentos, visões e experiências do autor, e têm sido empregados proveitosamente para abordar uma ampla fama de perguntas de pesquisa, inclusive tópicos delicados, privados ou difíceis", segundo sinaliza Meth (2019, p. 124) na esteira de diversos autores já habituados ao emprego dessa estratégia no interior da pesquisa qualitativa, principalmente na educação.

A fim de enriquecer a apreciação desse material, recorremos, no fim do período letivo, a uma breve entrevista semiestruturada. Estas foram as questões: Como sua experiência de escrever o diário se aproxima ou se distancia daquela vivida pelos personagens de

5 Registramos aqui nossos agradecimentos à professora Andréa Lacerda pela parceria na realização dessa atividade.

\begin{tabular}{|l|l|l|l|l|}
\hline Qovista Dialectus & Ano 9 & n. 16 & Janeiro-Abril 2020 & p. $65-81$ \\
\hline
\end{tabular}


Escritores da Liberdade? Como a escrita do diário se relaciona com a sua formação inicial docente e com o seu olhar sobre a comunidade escolhida como campo de observação? A realização da entrevista no término do período acadêmico indica nossa vontade de diagnosticar as práticas (de atenção, de cuidado, de trabalho sobre si) por elas postas em marcha.

É em torno dessa experiência pedagógica que o presente texto desvela, de modo bastante propedêutico, algumas considerações. Estas derivam do esforço por nós empreendido nos últimos anos: articular certos campos da Educação - como o dos fundamentos filosóficos da educação e a formação docente - e a experiência imagética, especificamente a cinematográfica (LIMA NETO, 2014; 2018; LIMA NETO; CHAGAS, 2015; LIMA NETO; ARAÚJO, 2018).

Fazemo-lo a exemplo de outras iniciativas similares de tantos outros pesquisadores, com diversas abordagens teóricas e metodológicas articulando cinema e fenômeno educativo (ARAÚJO, 2018; DUARTE, 2006; FISCHER, 2013; FRESQUET, 2013; NÓBREGA, 2010) e mobilizando as histórias de vida e narrativas (auto) biográficas na formação docente (BERTAUX， 2010; DELORY-MOMBERGER， 2008; 2014; LACERDA; SOUZA; PASSEGGI, 2008).

O desenvolvimento dos métodos etnográficos e estudos qualitativos potencializam as experiências, fontes e construção de dados que envolvem as escritas de si. (Bertaux, 2010). Instrumentos e procedimentos de investigação com epístolas, diários, portfolios, documentos pessoais, narrativas escritas e orais variadas fulguram com maior frequência neste cenário que perscruta os sentidos constituídos e constituintes do outro.

Tais procedimentos, nessa perspectiva, compõem, então, métodos e metodologias que trazem como cerne o falar de si mesmo, o expressar de uma compreensão sobre o mundo para ressignificar experiências e subjetividades. Operam como dispositivos de formação e provocação subjetiva, social e cultural, perpassando funções psíquicas como memória, atenção, reflexão, internalização de conteúdos e apropriação de conhecimentos.

Ao trazer tais procedimentos para o contexto de formação inicial docente, perguntamo-nos: como o sujeito estudante-futuro professor, no seu devir e construção da profissão, pensa, sente e fala do que vê, do que sente, do que pensa? Como os sujeitos, enfim, narram a si mesmo? Podemos afirmar que, "ao narrar-se, a pessoa parte dos sentidos, significados e representações que são estabelecidas à experiência. A arte de narrar, como uma

\begin{tabular}{|l|l|l|l|l|}
\hline Qovista Dialectus & Ano 9 & n. 16 & Janeiro-Abril 2020 & p. $65-81$ \\
\hline
\end{tabular}


descrição de si, instaura-se num processo metanarrativo porque expressa o que ficou na sua memória." (Souza, 2006, p. 104).

Desse modo, no processo de articulação destes campos e saberes, o fenômeno educativo ganha, marcadamente, contornos interdisciplinares e transdisciplinares, entrelaçando métodos das ciências humanas e sociais que correspondem ao conjunto das pesquisas autobiográficas no campo da formação inicial e/ou continuada de professores. É nessa direção que a presenta iniciativa ainda se coaduna com os esforços empreendidos por pesquisadores da Filosofia da Educação com vistas a convocar a noção de cuidado de si para pôr em questão variadas práticas e experiências pedagógicas, inclusive na formação de professores (GALLO, 2006; 2019; FREITAS, 2013; 2014; 2018; HERMANN, 2005; 2014; PAGNI, 2014).

Isso posto, as linhas seguintes apresentarão, simultaneamente, aspectos teóricos depreendidos da reflexão de Foucault acerca da escrita de si, articulando-os a trechos dos diários, acompanhados de partes das entrevistas realizadas com as estudantes. Essa escolha nos permite imergir de modo mais intenso na dinâmica do texto, no esforço de fissurar a dicotomia entre as palavras e as imagens. Para tanto, inicialmente, apontaremos alguns lugares do corpo e do discurso no contexto da cultura de si. Logo após, faremos emergir a experiência do olhar nessa mesma ambiência. Num terceiro momento, haurimos dos textos foucaultianos a possibilidade dessa dimensão imagética e a sua relação a transformação operada nos sujeitoscorpos que, em nosso caso, são licenciandas. Por fim, são sublinhados alguns elementos oriundos dessa experiência, com vistas a pensar a possibilidade de outras ferramentas teóricoempíricas capazes de colaborar eficazmente no processo de formação docente.

\section{Nota um: corpo e discurso no contexto da cultura de si ou "que seja arte"}

Foucault (1988) já havia atentado, no fim de A Vontade de Saber, para o tipo de prática que considera o corpo e a sexualidade como realidades biopolíticas. Desde então, distanciando-se da tradicional hipótese repressiva acerca do sexo, ele investe no mesmo deslocamento teórico feito tanto no que concerne às práticas discursivas quanto ao poder: procura pensar sobre como o desejo foi feito objeto das veridicções (REVEL, 2005, pp. 178182), "entendidas como as formas pelas quais se articulam, sobre um campo de coisas, discursos capazes de serem ditos verdadeiros ou falsos" (FOUCAULT, 2001c, p. 1451). O que distingue a sexualidade das outras dimensões da vida é que as interdições a ela endereçadas "são sempre

\begin{tabular}{|l|l|l|l|l|}
\hline Qovista Dialectus & Ano 9 & n. 16 & Janeiro-Abril 2020 & p. $65-81$ \\
\hline
\end{tabular}


ligadas à obrigação de dizer a verdade sobre si mesmo" (FOUCAULT, 2001d, p. 1602), e tal injunção concretiza-se no contexto de uma ascese. Compreende-se, portanto, que, ao centrarse, a partir dos anos oitenta, na problemática da subjetividade, Foucault o faz no campo das relações entre sujeito e verdade.

No curso Subjetividade e Verdade (1981), o autor começa a se aprofundar nesse elo ao tomar o domínio dos comportamentos sexuais na Antiguidade greco-romana como "superfície de refração" (FOUCAULT, 2010, p. 03). Na aula do dia 25 de março de 1981, ele resume o tipo de problema diagnosticado: o modelo que caracteriza as condutas sexuais dos indivíduos nas sociedades helenística e romana encontra-se "acompanhado, redobrado, reproduzido no interior de todo um longo discurso [...] que parecia redizer o real em termos de prescrição" (FOUCAULT, 2014, p. 252). Antes, no entanto, de se perguntar sobre o que estes discursos de fato efetuavam, fazia-se mister perguntar-se o que eles eram.

Não se tratava nem exatamente um código de regras, nem uma explicação teórica sobre o casamento ou os prazeres, mas sim técnicas (tekhnai) cujo objeto de ação era a própria vida das pessoas (peri ton bion). Eram técnicas no sentido que operavam "sobre um determinado objeto transformações em vista de certos fins" (FOUCAULT, 2014, p. 253), o que facultava

ao indivíduo efetuar, sozinhos ou com a ajuda de outros, um certo número de operações sobre seus corpos e sua alma, seus pensamentos, suas condutas, seu modo de ser; de se transformar a fim de alcançar um certo estado de felicidade, de pureza, de sabedoria, de perfeição ou de imortalidade (FOUCAULT, 2001d, p. 1604).

Aqui torna-se claro que o discurso está intrinsecamente atado à modificação da vida, daquilo que os gregos entendiam por bios. Todavia, o filósofo nos lembra que essa concepção não tem a acepção com o qual estamos acostumados a lidar, a saber, o de vida biológica ou, conforme esclarece Agamben (2010, p. 09), de zoé, “que exprimia o simples fato de viver comum a todos os seres vivos". Tratava-se, ao invés, de uma forma de vínculo estabelecido com as coisas e com o mundo ao redor, e nisto está implicado o fim que nos propomos a nós mesmos com tal conexão. Dizendo diferentemente: uma "vida qualificada, um modo particular de vida" (AGAMBEN, 2010, p. 09). Logo, o discurso, enquanto técnica, é portador de uma natureza claramente teleológica. Por meio dele será possível formar o bios.

\begin{tabular}{|l|l|l|l|l|}
\hline Ronista Dialectus & Ano 9 & n. 16 & Janeiro - Abril 2020 & p. $65-81$ \\
\hline
\end{tabular}


Quando pensado sob esse prisma, o discurso será uma arte, isto é, uma técnica de constituição do sujeito. "Sem saber como começar, mas já começando" - segundo evocamos no início deste artigo -, a estudante Luana se acerca, também ela, dessas artes da existência através da escrita. Pouco depois, ainda no primeiro dia do manuscrito, provavelmente no início de julho de 2017, ela diz:

Figura 1: Trecho do diário de Luana
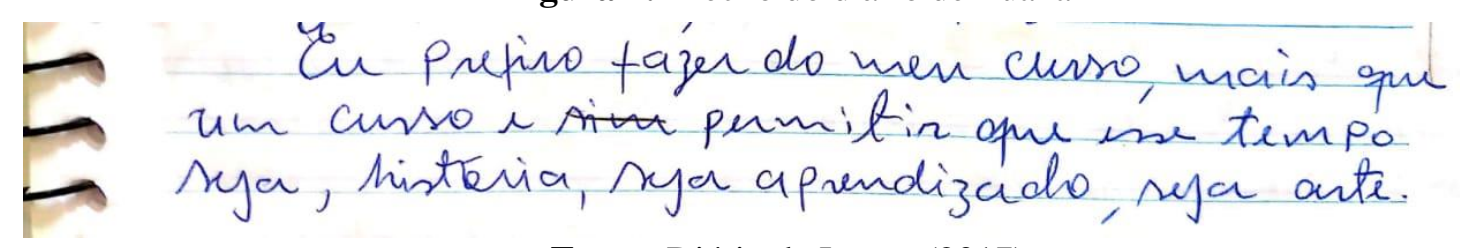

Fonte: Diário de Luana (2017)

Com os gregos e com Foucault, a subjetivação pelo discurso e, especificamente, pela escrita, já é experiência histórica de modificação de si que Luana parece intuir bem. O apontamento de Agamben acerca dessa outra dimensão é crucial, uma vez que ao compreender o bios como um modo singular de viver surge a "questão da subjetividade em sua dimensão ética. Fala-se de um sujeito comprometido com uma ética por vir; um sujeito movido e atravessado por atos e atitudes inspirados no cuidado de si e dos outros” (FREITAS, 2015, p. 419). É levando essa intuição em conta que nos deteremos, nas próximas linhas, na peculiaridade da escritura no universo das práticas de si.

\section{Nota dois: o corpo e o olhar ou "não me olhe"}

A função eminentemente produtiva do discurso aparece na escritura de si de modo emblemático: o logos do discurso, recolhido nas leituras, transformava-se em ethos, isto é, em um modo de ser. Aquilo que havia sido escutado adquire, por meio dela, uma "virtualidade física" (FOUCAULT, 2010, p. 321), ou seja, era visibilizado de algum modo na existência incorporada do sujeito. Trata-se do que Plutarco chamava de função etopoiética da escrita: a transformação dos discursos verdadeiros em princípios racionais de ação, o que ocorria por meio dos hupomnêmata e das correspondências (FOUCAULT, 2001e, p. 1237).

Os primeiros eram uma espécie de guia de conduta, no qual se anotavam "citações, fragmentos de obras, exemplos e ações", que serviriam como "memória material das coisas lidas, ouvidas ou pensadas" (FOUCAULT, 2001e, p. 1237). A escrita reúne importantes e

\begin{tabular}{|l|l|l|l|l|}
\hline Qevista Dialectus & Ano 9 & n. 16 & Janeiro-Abril 2020 & p. $65-81$ \\
\hline
\end{tabular}


Avelino Aldo de Lima Neto / Hugo Filgueiras de Araújo / Patrícia Carla de Macedo Chagas

distintos elementos das leituras feitas, unificando-as no próprio copista. É no gesto de escrever, na constituição dos hupomnêmata e no retorno posterior a eles que o sujeito se produz. Afinal,

o papel da escrita é constituir, com tudo o que a leitura constituiu, um 'corpo'(...). E é preciso compreender esse corpo não como um corpo de doutrina, mas sim - segundo a metáfora da digestão, tão frequentemente evocada - como o próprio corpo daquele que, transcrevendo suas leituras, delas se apropriou e fez sua a verdade delas: a escrita transforma a coisa vista ou ouvida 'em forças e em sangue'. Ela se torna no próprio escritor um princípio de ação racional. (FOUCAULT, 2001e, p. 1241) (grifo nosso).

A visceralidade da coisa vista ou ouvida se instala, pela escrita, no corpo, incidindo, destarte, sobre o modo como essa prática toca a existência. No caso das licenciandas, nem sempre a leitura e a escrita realizam-se com tranquilidade no cotidiano, como podemos notar no trecho abaixo, de 14 de agosto de 2017:

Figura 2: Trechos do diário de Luana

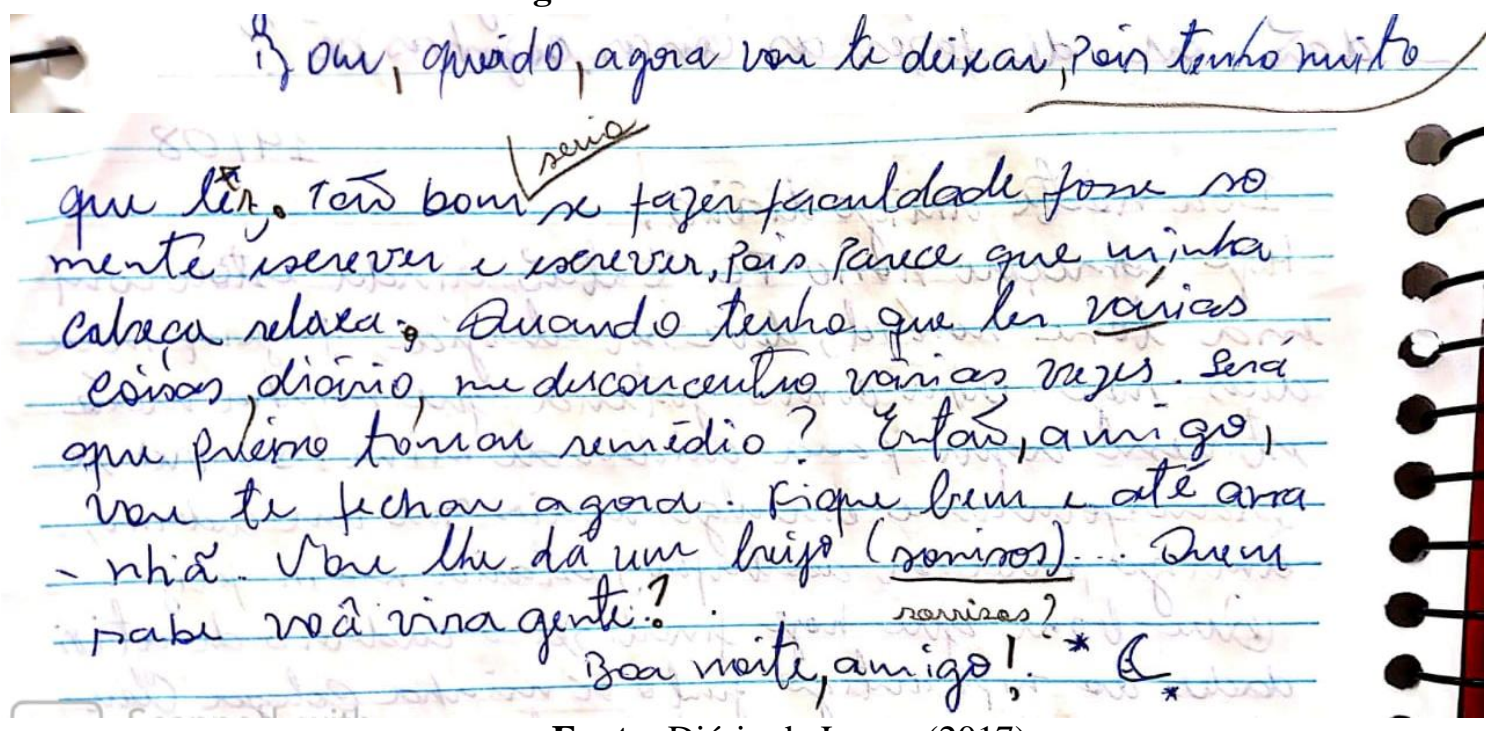

Fonte: Diário de Luana (2017)

No relato, embora a escrita apareça como um certo tipo de analgésico para o sofrimento, o desconforto é provocado pela incapacidade de lidar com o excesso de demandas de leitura. Percebe-se a dissociabilidade entre as duas práticas, mas, ao mesmo tempo, a afirmação do papel da escrita enquanto instrumento de transformação do bios. A metáfora da digestão evocada por Foucault o ratifica. A peculiaridade dessa arte da existência é que ela, sendo discurso-técnica, é concomitantemente discurso grafado materialmente, numa primeira

\begin{tabular}{|l|l|l|l|l|}
\hline Qevista Dialectus & Ano 9 & n. 16 & Janeiro-Abril 2020 & p. $65-81$ \\
\hline
\end{tabular}


instância, sob os signos e normas de uma gramática. Em segunda instância, tal discurso trabalha sobre uma outra matéria: o próprio corpo.

A estudante Bruna, por seu turno, em conflitos sentimentais, refere-se ao diário no dia 17 de julho de 2017 como se estivesse falando com uma pessoa:

Figura 3: Trechos do diário de Bruna

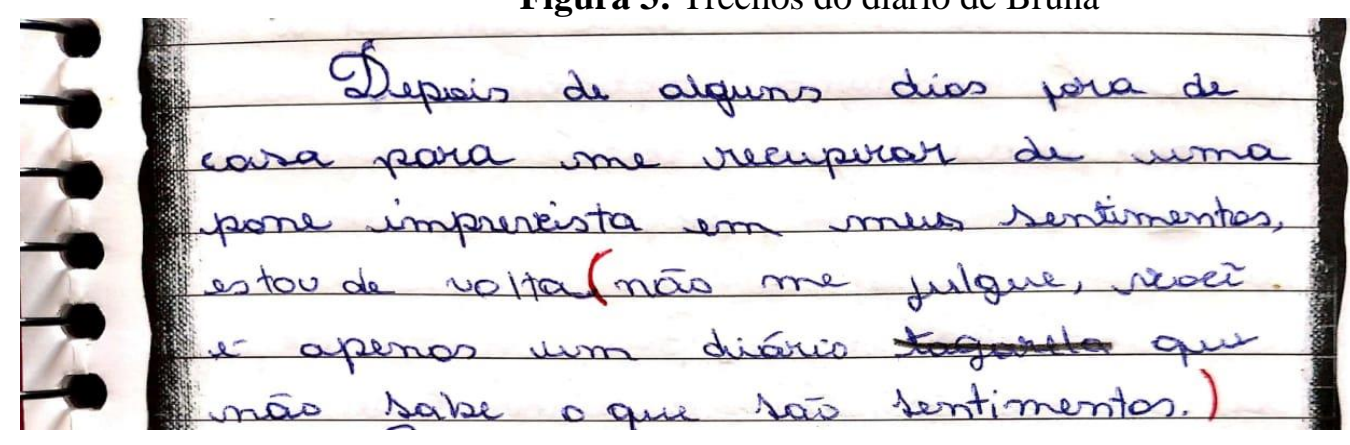

Fonte: Diário de Bruna (2017)

Por que o receio do julgamento daquele que vê o que ela escreve, se o que está diante dela parece ser apenas um papel? Uma possibilidade de resposta a essa questão passa por uma outra ambivalência na natureza desta técnica. Como se nota, a metáfora da digestão dá lugar privilegiado ao corpo e, nele, aos sentidos que colaboram para que tal processo se concretize. A coisa vista ou ouvida, que se materializa no sujeito, remete-nos ao papel da visão e da escuta. Dito isto, queremos situar-nos, agora, nas entrelinhas da pesquisa foucaultiana, explorando uma relação que ele não desenvolveu, embora tenha apontado a sua existência. Trata-se do elo entre a escrita e o olhar.

No elo semântico escrita-olhar encontramos significações e ressignificações que apontam uma dupla jornada formativa apontada por Josso (2004) como o caminhar para si e o caminhar com. Essas possibilidades de caminho são pertinentes quando tratamos de formação de professores, um processo que demanda oportunizar diversas experiências para a apropriação de conhecimentos sobre a docência. Para pensarmos essas possibilidades, Josso aponta:

\footnotetext{
O trabalho com as pessoas em formação favoreceu a formulação progressiva de um conjunto de problemáticas que emergem da abordagem de histórias de vida em formação: a subjetividade e a intersubjetividade, o sujeito em formação e o atores nos quais este se encarna, a auto-orientação e a autoformação, o consciente e o não-consciente, a experiência formadora, o saber-viver, a ligação e a partilha, a convivência, a divagação, o projeto e a pesquisa, a existencialidade e os seus lugares de predileção, a formação dos conhecimentos e o conhecimento da formação, os processos e dinâmica da vida, a interioridade e exterioridade, a
}

\begin{tabular}{|l|l|l|l|l|}
\hline Rovita Dialectus & Ano 9 & n. 16 & Janeiro - Abril 2020 & p. $65-81$ \\
\hline
\end{tabular}


mestiçagem e o nomadismo, o imaginário e o mito-poiético. (JOSSO, 2004, p. 159).

No imaginário e significações multifacetadas que constituem a formação, a escrita sobre este processo e sobre si atrai olhares ímpares. É pela escrita do que também foi visto que o corpo se constitui. Cremos que o pressuposto fundamental do papel do olhar na escritura de si é muito simples, e já está implícito na angústia de Bruna: não existe nem leitura, nem escrita sem um olhar. Embora a escuta também esteja ligada à formação da memória e à ascese, é somente pela visão que a coisa lida, ouvida ou pensada poderá tomar forma no papel. Daí, poder-se-iam inferir duas hipóteses: seria o olhar o fundamento indispensável da escritura de si? Ou seria, ao invés, somente um instrumento para que, por meio da leitura, o discurso atinja e transforme o sujeito? Para problematizar tais suposições, examinemos os lugares do olhar nas duas modalidades da escritura de si, a saber, nos huponmênata e nas correspondências.

Foucault enuncia três motivos pelos quais os huponmênata podem contribuir para a formação de si. O primeiro é por ele estar ligado à leitura. Tal característica leva aquele que escreve a ligar-se aos outros, a sair de si mesmo em busca de auxílio de ensinamentos válidos e, em seguida, retornar a si mesmo para se conduzir de modo apropriado. Por isso, para Sêneca, "não se devem dissociar leitura e escrita" (FOUCAULT, 2001e, p. 1239). Primeiramente, têmse, então, o olhar enquanto meio de condução e ligação com um outro.

O segundo motivo relaciona-se ao fato de que tal prática é voluntariamente ligada ao recolhimento de elementos díspares. O que importava era deter-se numa verdade local e na sua possibilidade de uso circunstancial, o que fazia da escritura dos huponêmata uma maneira de unir a verdade já dita com uma circunstância pontual (FOUCAULT, 2001e, p. 1240). A busca do que o outro disse, porém, não é uma fuga da própria realidade, mas uma espécie de exploração dela. Em segundo lugar, portanto, tem-se o olhar enquanto modo de experimentar a disparidade e a dinamicidade da vida.

O terceiro motivo lembra que a unificação dos discursos ocorre no próprio escritor. Ele é o resultado tanto do gesto de escrever quanto de ler. Para ilustrar tal processo, Sêneca utiliza algumas imagens: a colheita do néctar pela abelha, a digestão dos alimentos e a soma. Dizendo de outro modo: o papel da escritura é a constituição do eu, não a sua representação. Em terceiro lugar, portanto, constatamos que pelo olhar (mas também pela escuta), inicia-se um processo de transformação cujo ápice é a escritura, quando o que foi visto transforma-se

\begin{tabular}{|l|l|l|l|l|}
\hline Qevista Dialectus & Ano 9 & n. 16 & Janeiro-Abril 2020 & p. $65-81$ \\
\hline
\end{tabular}


no próprio corpo do leitor; além disso, a imagem não é semelhança com o real, mas evocação de um pertencimento espiritual.

No que concerne às correspondências, Foucault lembra que há uma certa proximidade delas com os huponmênata, haja vista que estes últimos poderiam servir de material primeiro para a elaboração de cartas. Nelas, o autor e o correspondente admoestam-se mutuamente. É modo de treinamento recíproco. Mas a figura do mestre espiritual continua com algum relevo. Ele pode dizer ao discípulo: "Reivindico-te; és obra minha" (FOUCAULT, 2001e, p. 1244). Porém, ao lembrar que as correspondências não podem ser consideradas uma mera continuidade dos huponmênata, como se bastasse enviá-los para se tornarem correspondências. Foucault faz uma ressalva que revela uma outra dimensão do olhar na Escritura de Si. A troca de cartas "constitui também uma certa maneira de cada um se manifestar a si próprio e aos outros. A carta faz o escritor 'presente' para aquele a quem a dirige. [...] presente de uma espécie de presença imediata e quase física" (FOUCAULT, 2001e, p. 1244).

Essa dimensão nos é mostrada por Luana ao dirigir-se ao seu diário: "Fique bem e até amanhã. Vou lhe dar um beijo (sorrisos)... Quem sabe você não vira gente?” (cf. Figura 2). Parece-nos que as correspondências inauguram uma outra dimensão de relação com o corpo, ausente nos huponmênata. Agora o sujeito torna-se de algum modo visível ao seu correspondente, isto é, cria uma imagem de si que permite a quem o lê sentir a sua presença. Ainda nas palavras de Luana, no primeiro dia do seu diário, é notória essa relação: "escrevo [o diário] como se estivesse falando [com alguém]". Nas correspondências, o objetivo é "fazer coincidir o olhar do outro e aquele que se lança sobre si mesmo ao comparar suas ações cotidianas com as regras de uma técnica de vida" (FOUCAULT, 2001e, p. 1249). Assim, enquanto na primeira modalidade da escrita de si o discurso constitui um modo de ser, um ethos, nas correspondências o discurso constitui uma imagem desse ethos.

Poderíamos resumir o papel do olhar por meio de dois fluxos: nos huponmênata, há um movimento que vai do olhar ao corpo, por meio da leitura que incorpora o discurso na subjetividade; nas cartas, há um movimento que vai do corpo ao olhar, através da manifestação do corpo. Assim, compreende-se que o olhar, além de possibilitar a leitura - função na qual desempenha um papel de certo modo instrumental, sobretudo nos huponmênata - também se encontra no ápice de um processo recíproco de cuidado de si, como o são as correspondências. Desse modo, a experiência do olhar impregna todo momento de subjetivação pelo discurso, seja

\begin{tabular}{|l|l|l|l|l|}
\hline Qovista Dialectus & Ano 9 & n. 16 & Janeiro-Abril 2020 & p. $65-81$ \\
\hline
\end{tabular}


como meio para que o discurso atinja o sujeito, seja como constituição de uma imagem que o outro verá. E ela vincula ambas as modalidades.

\section{Nota três: a dimensão visual da escritura de si ou o retorno dos Escritores da Liberdade}

Pensemos nos discursos enquanto técnicas e seus efeitos sobre o real - questão que, conforme anunciamos anteriormente, motivou Foucault em sua pesquisa sobre os aphrodisia. Ele chega à seguinte conclusão: não existe uma relação causal entre jogos de verdade e realidade, como se aqueles fossem capazes de engendrar esta última de modo positivo. Para bem compreender esse vínculo, o importante é “centrar-se na conexão que existe entre os jogos de verdade [...] e o real no interior do qual eles se inserem ou ao qual eles se referem" (FOUCAULT, 2014, p. 241). Se transpuséssemos estas ligações em forma de conjuntos, um seria o dos jogos de verdade, outro seria o real - que é composto pelas práticas humanas (FOUCAULT, 2014, p. 247) - e, ao centro, na intersecção, teríamos aquilo que Foucault denomina de experiência.

É na experiência que se materializa a relação entre subjetividade e verdade, e é nesta efetivação que se constatam os efeitos dos jogos de verdade sobre as práticas humanas (FOUCAULT, 2014, p. 241). Assim, uma análise política da verdade poderia ser feita ao se mostrar "quais são os efeitos recíprocos da conexão que existe entre as práticas humanas e os regimes de veridicção que a eles estão conectados" (FOUCAULT, 2014, p. 241). Nessa conexão, na qual realiza-se a experiência de uma dada realidade, articulam-se "formas de relação consigo, técnicas de poder e discursos" (GROS, 2013, p. 83).

Para pensar as relações entre a escritura de si e os jogos de verdade, escolhemos investir na novidade que a exploração de sua dimensão visual pode trazer. Como vimos, as correspondências criam uma modalidade distinta de presença e de exercício do cuidado de si, uma visibilidade possibilitada pela linguagem. É nesse contexto que se situam as duas questões feitas às estudantes, após o término do semestre letivo e da escrita de seus diários. À pergunta "Como a sua experiência de escrever o diário se aproxima ou se distancia daquela vivida pelos personagens de Escritores da Liberdade?", ambas reconhecem a aproximação.

Bruna enfatiza o caráter de liberdade na escrita: "assim como eles, tive total liberdade para escrever exatamente o que eu queria". Já Luana afirma que "como eles, há um desejo de transformação de vida, uma angústia, um anseio. Igualmente, todos passamos

\begin{tabular}{|l|l|l|l|l|}
\hline Qovista Dialectus & Ano 9 & n. 16 & Janeiro-Abril 2020 & p. $65-81$ \\
\hline
\end{tabular}


dificuldades, somos testados e testamos ou tentamos. E a resistência será a grande diferença para essa mudança que ambos escritores da liberdade desejamos!”. Liberdade e mudança emergem, portanto, como palavras-chave na compreensão da prática de escrita do diário, claramente extrapolando o mero exercício do escrever e acercando-se de uma técnica que acompanha ou colabora no processo de subjetivação das docentes em formação.

$\mathrm{Na}$ verdade, a relação que se estabelece por meio da carta está mais associada ao olhar e ao exame. Ao se mostrar naquilo que escreve, o correspondente torna sua vida absolutamente visível ao outro e, além disso, faz com que este último assuma o lugar da observação sobre sua vida moral. Essa dinâmica aparece nas respostas à segunda questão, qual seja, Como a escrita do diário se relaciona com a sua formação inicial docente e com o seu olhar sobre a comunidade escolhida como campo de observação?, Bruna admite que "poder fazer essas observações sobre a vida real e não apenas ler um texto [...] foi bastante instigante. O diário me permitiu ser a autora do meu próprio texto, fazer minhas próprias observações”. Luana, por sua vez, respondendo a esse mesmo questionamento, afirma:

me ver no diário representa minha imagem como espelho, [no qual] vejo meus defeitos e minha beleza. E penso que meus futuros alunos também viverão ou passam por esses confrontos e desafios para chegar a uma educação de 'qualidade'. [...] Pena que muitos [...] professores não são possuidores de sensibilidade para 'perceber' seus alunos, e eu não quero ser assim. Então escolho me ver agora. (grifo nosso).

Entre os antigos, a objetivação da alma realizada por meio da escrita provoca efeitos de subjetivação no emissor e no receptor da carta. O diário funcionou como esse outro que recebia a correspondência das estudantes. Ambas reconhecem a singularidade desse vínculo com a realidade, criado através da escrita, e a sua importância na observação do mundo e de si mesmas, o que é ainda mais claro na resposta de Luana. Só pode ver bem quem se vê bem e se transforma. Objetivar para subjetivar-se: eis aí o segredo da escrita de si, tanto entre os antigos quanto entre nossas licenciandas.

\section{Considerações finais}

Todo o conjunto de práticas de si relaciona-se com uma ideia de verdade enquanto verdade-postura, verdade-prova, verdade-arma no combate agonístico do cuidado de si

\begin{tabular}{|l|l|l|l|l|}
\hline Qovista Dialectus & Ano 9 & n. 16 & Janeiro-Abril 2020 & p. $65-81$ \\
\hline
\end{tabular}


(SFORZINI, 2014, p. 99-101). Nossa hipótese, porém, é que a escritura concentra em si, mais intensamente, o aspecto da verdade-postura, dado seu caráter sintético do processo que começou com a escuta ou a visão do mestre. Por meio dela, passamos da escrita ao olhar enquanto modo de manifestação da verdade, que se inscreve no corpo e se torna postura. Esse espelho no qual o sujeito se vê, como afirma Luana, modifica o caráter da experiência, à medida que cria um outro regime de inteligibilidade, não mais baseado na mera representação dos signos. Com isso, não afirmamos que a escrita seja desprezada. Ao contrário, ela continua indispensável. No entanto, inaugura-se uma nova relação com a verdade no seu interior, não mais focada na correspondência entre o escrito e o real, mas, graças à visibilidade, numa “ostentação da verdade no corpo" (SFORZINI, 2014, p. 101), numa subjetivação sensível.

O texto A Escritura de Si, sabemos, não nos fala explicitamente do olhar, mas deixanos muitas pistas sobre a dimensão visual desta técnica. Aqui, o que constatamos são as indicações dos germes de uma outra forma de experiência, que embora esteja circunscrita no real em suas interfaces com as veridicções, traz implicações diferentes para a compreensão da constituição de si. A instalação de uma outra inteligibilidade reconfigura as conexões entre as formas de relação consigo, as técnicas de poder e os discursos - constituintes da conexão na qual se realiza a experiência. Essa modalidade não exclui, como afirmamos, a escritura. Mas, no mínimo, ela a reconfigura.

A imagem, na escritura de si, também parece nos liberar outros sentidos para a subjetivação e, nesse contexto, para a formação docente. De modo geral, a experiência das licenciandas com a escrita dos diários mostrou-nos ser possível articular a experiência vivida aos saberes acadêmicos, pois permitiu aos sujeitos estabelecerem mais facilmente vínculos entre a formação universitária e o cuidado de si.

No cuidado de si reside um olhar que retorna sobre si, fazendo emergir implicações e ressignificações possíveis sobre o vivido e experienciado, "a partir de lembranças particularizadas das histórias de vida. Revelar-se, apresentar-se, autorizar-se. Dizer de si." (SOUZA, 2004, p. 104)

Mesmo que ainda haja tensões na compreensão da indissociabilidade entre a leitura e a escrita enquanto modalidades de uma mesma experiência de transformação de si, entre as quais o pensamento se situa (LARROSA, 2014, p. 139), promoveu-se uma estilização da existência que cria outras resistências cotidianas (PAGNI, 2014, p. 163-164). Escolher-se verse agora através do diário, como diz Luana na entrevista, é um indicador de uma outra

\begin{tabular}{|l|l|l|l|l|}
\hline Qovista Dialectus & Ano 9 & n. 16 & Janeiro-Abril 2020 & p. $65-81$ \\
\hline
\end{tabular}


inteligência, desveladora de subjetividades outras nas interfaces entre saberes e poderes do cotidiano docente.

Tomar para si o desvelar pela escrita possibilitada nos faz repensar a relevância de métodos de pesquisa e, sobretudo de práticas formativas nas licenciaturas, que proporcionem a construção subjetiva propositiva de um ofício profissional em seu devir.

A narração de si na trajetória inicial da docência contempla o potencial do ser professor como um outro si possível a ser constituído. As futuras professoras Luanas podem, desse modo, ressignificar o olhar e o lugar na docência com novos projetos de si.

\section{Referências}

AGAMBEN, Giorgio. Homo Sacer: o poder soberano e a vida nua I. Belo Horizonte: Editora UFMG, 2010.

ARAÚJO, Allyson Carvalho. Esporte no cinema contemporâneo: representações e outras sensibilidades culturais. Natal: Editora do IFRN, 2018.

BERTAUX, Daniel. Narrativas de vida: a pesquisa e seus métodos. Natal, São Paulo: EDUFRN, Paulus, 2010.

DELORY-MOMBERGER, Christine. As histórias de vida: da invenção de si ao projeto de formação. Natal, Porto Alegre, Salvador: EDUFRN, EDIPUCRS, UNEB, 2014.

Biografia e formação: figuras do indivíduo-projeto. São Paulo, Natal: Paulus, EDUFRN, 2008.

DUARTE, Rosália Maria. Cinema e educação. 2. ed. Belo Horizonte: Autêntica, 2006.

FISCHER, Rosa Maria Bueno. Televisão \& educação: fruir e pensar a TV. 4. ed. Belo Horizonte: Autêntica, 2013.

FREITAS, Alexandre Simão. A formação humana no contexto da consumação metafísica do sujeito: ética da potência de Agamben. Educação (Porto Alegre, impresso), v. 38, n. 3, p. 415423, set.-dez. 2015.

A parresía pedagógica de Foucault e o êthos da educação como psicagogia. Revista Brasileira de Educação (Impresso), v. 18, p. 325-338, 2013.

. Os perigos éticos de Foucault e sua ontologia sem cabimento: o si mesmo - quem é? In: LIMA NETO, Avelino Aldo; SILVA, Luís Lucas Dantas; SANTIAGO, Maria Betânia do Nascimento. Filosofia, educação e subjetividades: interfaces (im)pertinentes. Recife: Editora UFPE, 2014.

\begin{tabular}{|l|l|l|l|l|}
\hline Qovista Dialectus & Ano 9 & n. 16 & Janeiro-Abril 2020 & p. $65-81$ \\
\hline
\end{tabular}


O toque frágil dos acontecimentos entre a estética da existência e a antropologia da plasticidade: notas para um devir-deficiente da pedagogia. In: LIMA NETO, Avelino Aldo; SILVA, Luís Lucas Dantas; SANTIAGO, Maria Betânia do Nascimento. Filosofia, educação e subjetividades: outros sentidos para o educativo. São Paulo: LiberArs, 2018.

FRESQUET, Adriana Mabel. Cinema e educação: reflexões e experiências com professores e estudantes dentro e fora da escola. 1. ed. Belo Horizonte: Autêntica, 2013

FOUCAULT, Michel. A hermenêutica do sujeito: curso dado no Collège de France (19811982). Trad. Márcio Alves da Fonseca, Salma Tannus Muchail. São Paulo: Martins Fontes, 2010.

Foucault. In : . Dits et Écrits II : 1976-1988. Paris: Gallimard : 2001c.

. História da sexualidade 1: A vontade de saber. Rio de Janeiro: Graal, 1988.

. História da sexualidade 2: O uso dos prazeres. Rio de Janeiro: Graal, 1984.

2001d.

Les techniques de soi. In : Dits et Écrits II : 1976-1988. Paris: Gallimard :

. L'écriture de soi. In : Dits et Écrits II : 1976-1988. Paris: Gallimard : 2001e.

Nietzsche, a genealogia e a história. In: . Microfísica do Poder. Rio de Janeiro: Graal. 1979.

Subjectivité et Vérité: cours au Collège de France. 1980-1981. Paris: EHESS, Gallimard, Seuil, 2014.

GALLO, Sílvio. Cuidar de si e cuidar do outro. In: KOHAN, Walter Omar; GONDRA, José. Foucault 80 anos. Belo Horizonte: Autêntica, 2006. 5-12, 2019.

Michel Foucault e a construção conceitual do cuidado de si. Linha Mestra, v. 37, p.

GROS, Frédéric. Subjectivité et Vérité: quelques concepts inédits. In: LORENZINI, Daniele ; REVEL, Ariane; SFORZINI, Arianna (orgs.). Michel Foucault: éthique et vérité 1980-1984. Paris: Vrin, 2013.

HERMANN, Nadja. Ética \& Educação: outra sensibilidade. Belo Horizonte: Autêntica, 2014. Ética e estética: a relação quase esquecida. Porto Alegre: EDIPUC, 2005.

JOSSO, Marie-Christine. Experiências de vida e formação. Tradução José Claudio e Júlia Ferreira. Adaptação à edição brasileira: Maria Vianna. São Paulo: Cortez, 2004.

\begin{tabular}{|l|l|l|l|l|}
\hline Qovista Dialectus & Ano 9 & n. 16 & Janeiro-Abril 2020 & p. $65-81$ \\
\hline
\end{tabular}


LACERDA, Gorete Maria; SOUZA, Elizeu Clementino; PASSEGGI, Maria da Conceição. Pesquisa (auto)biográfica: cotidiano, imaginário e memória. São Paulo, Natal: Paulus, EDUFRN, 2008.

LARROSA, Jorge. Tremores: escritos sobre experiência. Belo Horizonte: Autêntica, 2014.

LIMA NETO, Avelino Aldo; CHAGAS, Patrícia Carla de Macedo. A Filosofia nos espelhos da formação docente: o lugar das disciplinas filosóficas no currículo das licenciaturas do IFRN. Saberes (Natal), v. 1, p. 251-264, 2015.

O intelectual, a subjetivação e a escrita: algumas tensões entre a carne e o verbo. In: ; SILVA, Luís Lucas Dantas; SANTIAGO, Maria Betânia do Nascimento. Filosofia, educação e subjetividades: interfaces (im)pertinentes. Recife: Editora UFPE, 2014.

; ARAÚJO, Hugo Filgueiras. Para além do corpo belo: notas sobre corpo e educação a partir da leitura foucaultiana do Alcibíades. Educação e Filosofia (On Line), v. 32, p. 1-15, 2018 .

Ver com Foucault. In: O cinema como educação do olhar. São Paulo: LiberArs, 2018.

METH, Paula. "Desabafando" - O método do diário solicitado. In: BRAUN, Virginia et al. Coleta de dados qualitativos: um guia prático para técnicas textuais, midiáticas e virtuais. Trad. Daniela Barbosa Henriques. Petrópolis: Vozes, 2019.

NÓBREGA, Terezinha Petrucia. Uma fenomenologia do corpo. São Paulo: Livraria da Física, 2010 .

PAGNI, Pedro Ângelo. Experiência estética, formação humana e arte de viver: desafios filosóficos à educação escolar. São Paulo: Loyola, 2014.

PLATÃO. Timeu. Tradução de Maria José Figueiredo. Lisboa: Instituto Piaget, 2004.

República. Tradução de J. Guinsburg. São Paulo: Pespectiva, 200 REVEL, Judith. Expériences de la pensée: Michel Foucault. Paris: Bordas, 2005.

ROBINSON, T. As origens da alma: os gregos e o conceito de alma de Homero a Aristóteles. São Paulo: Anablume, 2010.

SFORZINI, Arianna. Michel Foucault : Une pensée du corps. Paris: PUF, 2014.

SOUZA, Elizeu Clementino de. O conhecimento de si: estágio e narrativas de formação de professores. Rio de Janeiro: DP\&A; Salvador/BA: UNEB, 2006.

TEIXEIRA, Fábio Luís Santos; CAMINHA, Iraquitan de Oliveira; LIMA NETO, Avelino Aldo. Duas funções do olhar em Foucault: panoptismo e transoptismo. Aurora: revista de arte, mídia e política, São Paulo, v.10, n.29, p. 108-126, jun.-set. 2017.

\begin{tabular}{|l|l|l|l|l|}
\hline Qevista Dialectus & Ano 9 & n. 16 & Janeiro-Abril 2020 & p. $65-81$ \\
\hline
\end{tabular}

